\title{
ADDENDUM
}

\section{A CHARACTERIZATION OF PSEUDOCOMPACTNESS}

\author{
P.R. MISRA \\ IMECC/UNICAMP \\ Caixa Posta1 6155 \\ 13100-Campinas-S.P.-BRASIL
}

\author{
VINODKUMAR \\ Kurukshetra University \\ Kurukshetra - 132119 \\ INDIA
}

(Received March 26, 1982)

To prove the main theorem of our paper [1], we have used continuity of the function $\Delta(f)$ without any explicit mention of it. Infact, using the methods of [2] to show the continuity of the stone extension of a continuous function, it is easy to establish the continuity of $\Delta(f)$ when $f$ is a continuous function from a space $\mathrm{X}$ to a pseudocompact space $\mathrm{Y}$ :

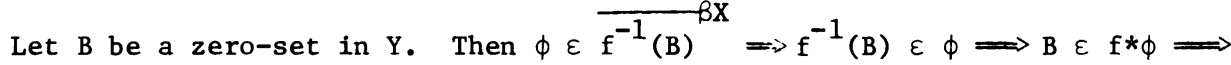
B $\varepsilon \Delta(f) \phi \Longrightarrow \Delta(f) \phi \varepsilon \bar{B}^{\beta Y}$. We use this information to check the continuity of $\Delta(\mathrm{f})$ at an arbitrary point $\phi \varepsilon \beta \mathrm{X}$.

Let $\bar{B}^{\beta Y}$ be an arbitrary zero-set neighborhood of $\Delta(f) \phi$, where $B$ is zero-set in $Y$. This can be supposed since $Y$ is pseudocompact. Let $\bar{B}^{\beta Y}$ be a zero-set in $B Y$ with $B^{\prime}$ a zero-set in $Y$ such that $\Delta(f) \phi \notin \bar{B}^{-\beta Y}$ and $\bar{B}^{\beta Y} \cup \bar{B}^{\beta Y}=\beta Y$. Since $\Delta(f) \phi \notin \bar{B}, B Y$ $\phi \notin{\overline{f^{-1}\left(B^{\prime}\right)}}^{\beta X}$. Now, since $B \cup B^{\prime}=\left(\bar{B}^{\beta Y} \cap Y\right) \cup\left(\bar{B}^{\beta Y} \cap Y\right)=\left(\bar{B}^{\beta Y} \cup \bar{B}^{, \beta Y}\right) \cap Y=Y$, $f^{-1}(B) \cup f^{-1}\left(B^{\prime}\right)=X$. Thus $\overline{f^{-1}(B)} \beta X f^{-1}\left(B^{\prime}\right)=\beta X$. We see that $\beta X-\bar{f}^{-1}(B)$ is a neighborhood of $\phi$, contained in $\mathrm{f}^{-1}(B)$, and hence is carried in to $\bar{B}^{Y}$ by $\Delta(f)$. This proves the continuity of $\Delta(f)$ at a point $\phi$ of $\beta X$.

For any continuous z-ultra function $f$, the proposition in the paper and $6 \mathrm{E} .1$ of [2] imply that $\Delta(f)$ is continuous. Thus, for the proof of the converse, the continuity of $\Delta(i)$ is a consequence of $i$ being z-ultra.

We are thankful to Professor S.N. Bhatt for pointing out the above omissions.

\section{REFERENCES}

1. MISRA, P.R. and VINODKUMAR. A characterization of pseudocompactness, Internat. J. Math. Math. Sci. 4 (1981), pp. 407-409.

2. GILLMAN, L. and JERISON, M. Rings of Continuous Functions, Von Nostrand, Princeton, 1960. 


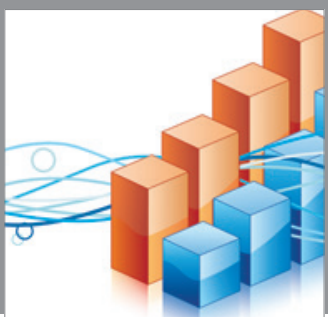

Advances in

Operations Research

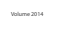

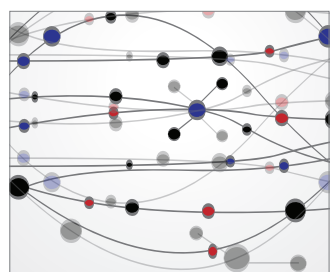

\section{The Scientific} World Journal
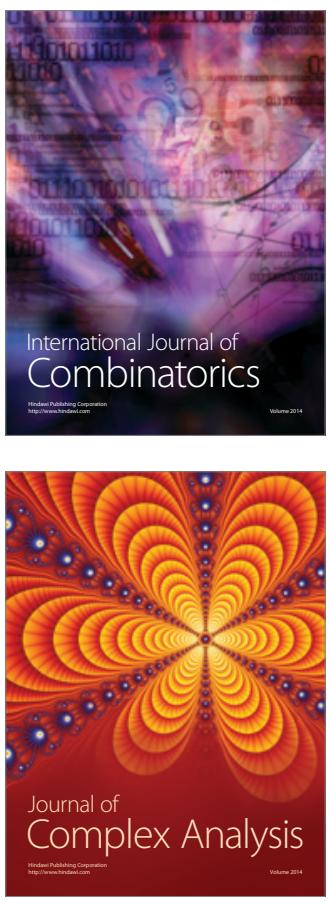

International Journal of

Mathematics and

Mathematical

Sciences
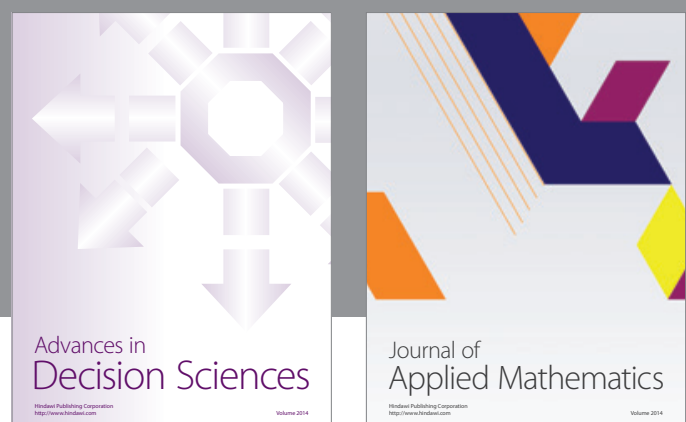

Journal of

Applied Mathematics
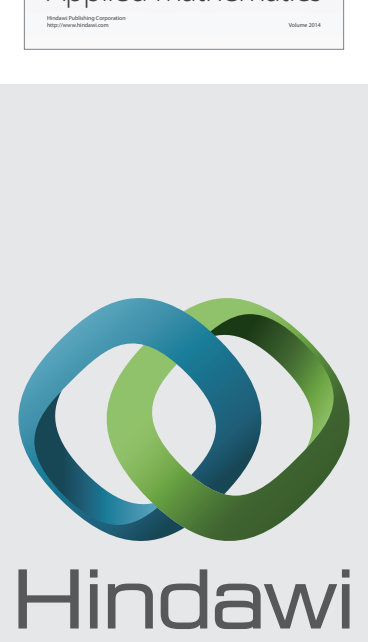

Submit your manuscripts at http://www.hindawi.com
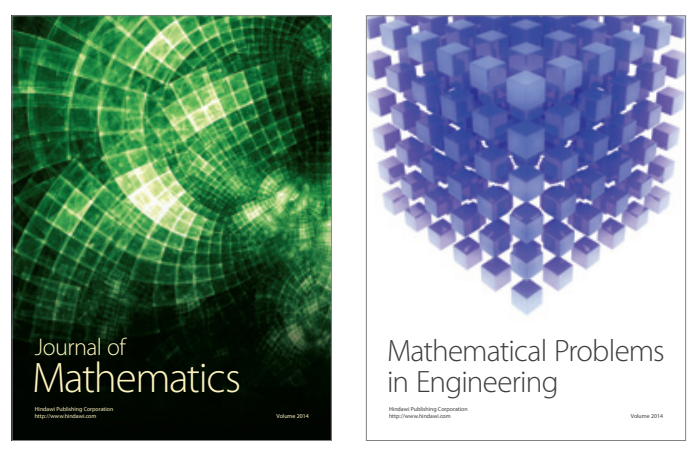

Mathematical Problems in Engineering
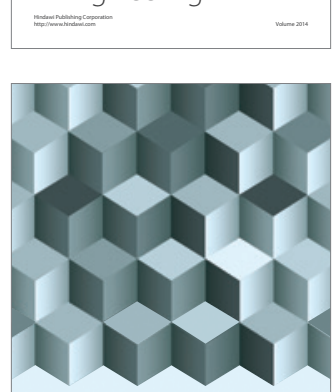

Journal of

Function Spaces
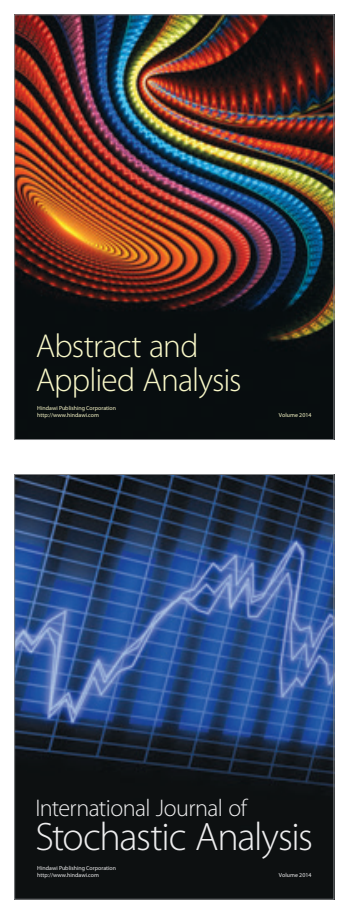

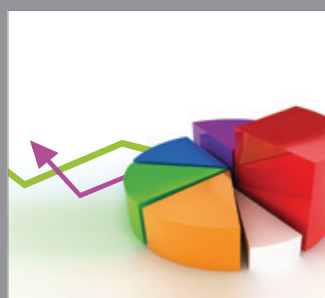

ournal of

Probability and Statistics

Promensencen
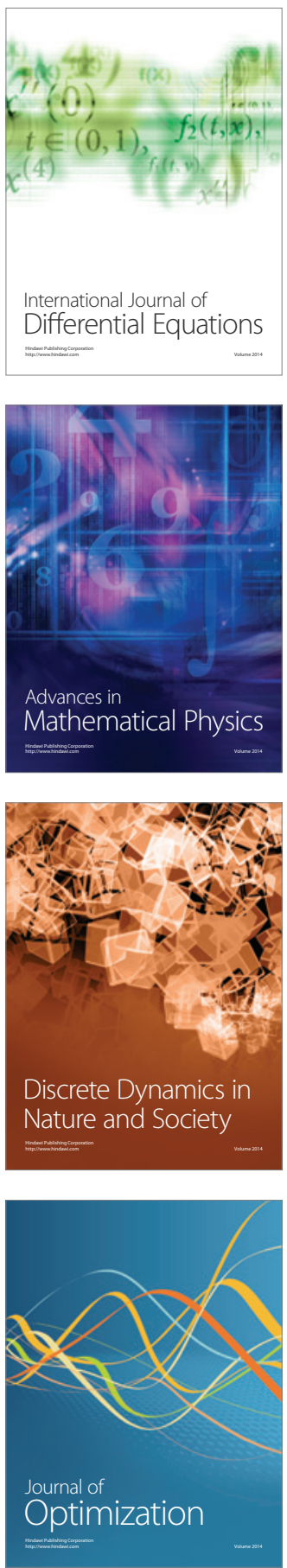